\title{
APPLICATION OF SHANNON'S ENTROPY MODEL AND GIS IN FLASH FLOOD FORECASTING ALONG NATIONAL HIGHWAY-6, HOA BINH PROVINCE, VIETNAM
}

\author{
Ha Thi Hang ${ }^{1}$, Pham Duy Hoa ${ }^{1}$ *Vu Ngoc Tru ${ }^{1}$ and Nguyen Viet Phuong ${ }^{1}$ \\ ${ }^{1}$ Faculty of Bridges and Roads, Hanoi University of Civil Engineering, Vietnam \\ *Corresponding Author, Received: 06 Sept. 2021, Revised: 26 Sept. 2021, Accepted: 17 Oct. 2021
}

\begin{abstract}
The flash flood is the most dangerous natural disaster to mountainous highways in tropical countries due to its special characteristics. It has occurred quite frequently on mountainous highways and directly threatened road infrastructure, economy, and lives every year. Meanwhile, detailed flash flood spatial prediction maps are rarely available on these highways. Shannon's Entropy model and GIS permit cheaper, more efficient, easy to use, and updated flash flood-prone areas forecasting. Therefore, this study applied Shannon's Entropy model and GIS to generate a detailed flash flood susceptibility map along National Highway-6 of Hoa Binh province of Vietnam. Twelve input factors that influence flash floods within the research area were used and collected from different sources. These mentioned factors corresponded to twelve thematic maps in the GIS environment. In this paper, the ROC curve method was used to evaluate the accuracy of the flash flood forecasting map and given a very good value (81.1\%). The flash flood forecasting map can help organizers and decision-makers have safety rescue solutions or give early warning to people who have lived along this highway for better flash flood prevention and management.
\end{abstract}

Keywords: Flash flood forecasting map, Shannon’s Entropy, GIS, National Highway-6, Vietnam.

\section{INTRODUCTION}

Flash floods and landslides are considered dangerous natural disasters in mountainous areas in general and mountainous highways in particular [1]. However, flash floods are usually more hazardous than landslides because they occur very suddenly, quickly, and without previous warning. Many factors contribute to flash flood occurrences, but extreme rainfall due to climate change is considered the main factor [2].

In the Northwestern mountainous regions of Vietnam, the increased frequency and intensity of flash floods and landslides cause tremendous damage to the production activities, road network, infrastructure, and a great number of lives [3]. Whereas, the mountainous highways play a vital role in transportation, economic development, and the military. Especially, many mountainous regions of Vietnam have the only highway that connects to the capital and many different localities. Although many modern engineering solutions (eg. slope stability insurance, new material replacement, flooding spot classification) were proposed and applied on these highways to improve the road network quality before the impact of natural disasters [4,5,6], flash floods have still occurred with increased frequency and intensity and destroyed many road infrastructures in recent years. However, detailed flash flood spatial predictive maps are rarely available on these important highways. Meanwhile, flash flood susceptibility maps can provide a useful and effective tool for flash flood risk management in the transportation sector by identifying the risk areas and using suitable safety and rescue measures [7].

In the recent decade, many studies on flash flood susceptibility mapping have been conducted for the area scale [8]; however, there are not many studies on flash flood forecasting along the highways. In [9], morphometric analyses were mainly used to estimate the flash flood risk levels. Whereas, geological and geomorphological data were extracted from remote sensing. Then, these data were combined with field data to estimate the flash flood risk along the Feiran-Katherine road, southern Sinai, Egypt, in the GIS environment. In [10], the flood triggering factors were selected based on field observations and climatic analysis. The analytical hierarchy process (AHP) was applied to determine the weight and combine the factors in the GIS environment.

In Vietnam, National Highway-6 (NH-6) of Hoa Binh province plays an important role in transportation, economy, and military. However, this route has often faced landslides and flash floods that caused damage to both properties and lives every year. Therefore, some studies on natural disaster risk assessment along this highway have been conducted in recent years $[1,7,11]$. The latest study on flash flood susceptibility mapping along this highway by using hybrid machine learning 
models [7]. Five hybrid machine learning models were used in this research to build flash flood susceptibility mapping. In the total number of used models, Decorate-Reduced Error Pruning Trees (DCREPT) ensemble model has had the best performance; however, this research has required users to have specific knowledge about machine learning algorithms, statistical methods, software and have prolonged data processing. Meanwhile, Shannon's Entropy (SE) model is a new model for evaluating flood potential [12]. This model is quite suitable for data-scarce basins. In addition, this model is relatively easy to use and has more accurate performance than some other statistical models $[8,13]$.

For the above-mentioned reasons, this paper has presented the detailed flash flood spatial prediction map along NH6, Hoa Binh province of Vietnam by using Shannon's Entropy model and GIS technology.

\section{RESEARCH SIGNIFICANCE}

Due to the complex terrain conditions, mountainous highways have often faced flash floods after extreme rainfall every year. Flash flood susceptibility mapping and assessment can provide a valuable tool to conduct suitable prevention solutions to ensure an area or infrastructure's safety. However, in the northwestern mountain of Vietnam, detailed flash flood susceptibility maps are rarely available on important highways. In this study, the SE model has been used to build a detailed flash flood spatial predictive map along NH6 in the Hoa Binh province of Vietnam with many advantages, such as being easy to use, update and has high performance. In addition, this model has not required deep knowledge about machine learning algorithms, software, or computer modeling. The result of this research can help organizers and decision-makers determine the flash flood susceptibility areas to conduct suitable safety and rescue measures or give early warning to people who have lived along this highway.

\section{METHODOLOGY}

\subsection{Study Area}

Hoa Binh province lies between the latitudes of $20^{0} 19^{\prime} \mathrm{N}-21^{0} 08^{\prime} \mathrm{N}$, and the longitudes of $104^{0} 48^{\prime} \mathrm{E}$ - $105^{0} 40^{\prime} \mathrm{E}$. The topography of this province is mainly hilly with narrow valleys. The length of $\mathrm{NH}$ 6 of Hoa Binh province is about $115 \mathrm{~km}$, from Km38 to $\mathrm{Km} 153$, and passes through five districts, including Luong Son, Ky Son, Hoa Binh city, Tan Lac, and Mai Chau (Fig.1). It is the only route that connects the Ha Noi capital with Northwestern mountainous provinces (Hoa Binh, Son La, Dien
Bien).

The geological condition of NH-6 includes many different lithology types, including Quaternary sedimentary rocks, Carbonate sedimentary rocks, Aluminosilicate-rich sedimentary rocks, Acid-magma rocks, and Mafic erupted rocks. Faults and other structures are present in these rock types [1].

The average rainfall of Hoa Binh province is about $180 \mathrm{~mm}$ in dry seasons and over $1200 \mathrm{~mm}$ in rainy seasons.

In general, the complex geo-environmental of NH-6 make suitable conditions for the flash flood risk occurrences.

In this study, the buffer of National Highway-6 is considered about $3 \mathrm{~km}$ because most of this route is sandwiched between the high mountains and the low valleys, so the range of the flash flood occurrence is very large. The past flash flood locations were also contributed to determining the research buffer.

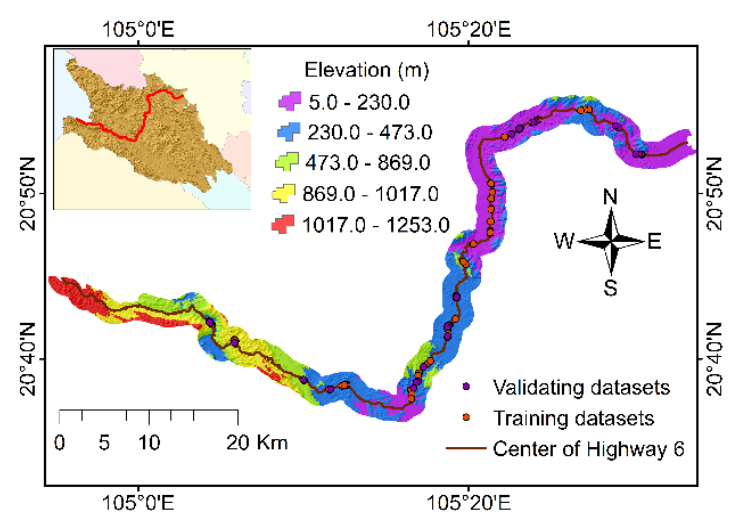

Fig.1 Flash flood inventory map along NH-6

\subsection{Flash Flood Inventory Map}

The flash flood inventory map plays a vital role in the flash flood spatial prediction mapping procedure. It reflects the relationship between past flash flood locations and their causative factors and takes part in assessing the performance of the prediction modeling.

Flash flood inventory map on NH6 in the Hoa Binh province of Vietnam has been generated with 88 flash flood locations which were investigated by field surveys during the period 2016-2019 [7,14]. In addition, 16 flash flood locations were also added to this inventory map according to the historical flood data of 2008, 2011, and 2015 of NH6 manager units.

This data was randomly divided into two parts: a training dataset (70\% flash flood inventory) was used for flash flood forecasting mapping, and a validating dataset (30\% remaining flash flood inventory) was applied for evaluation and verification of the model. 


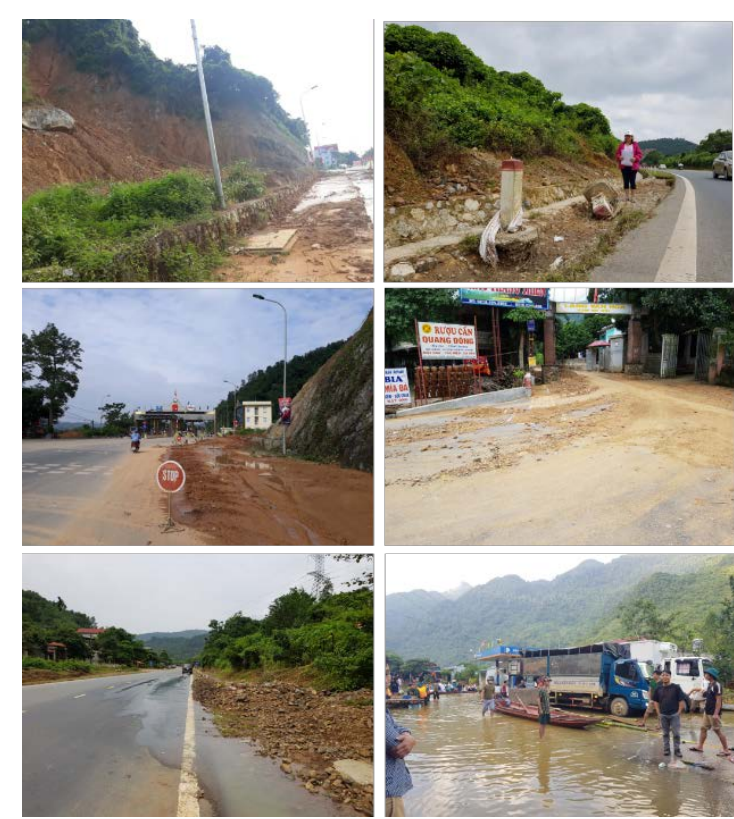

Fig.2 Selected flash flood locations along NH-6 in 2017, 2018, and 2019 field surveys.

\subsection{Flash Flood Causative Factors}

Flood influencing factors and their relationship with flood occurrences are very necessary to assess the susceptibility to flooding [15]. Therefore, the selected input factors had to be reliable and simply achievable [16].

Based on the available data and the relationship between the past flash flood locations and the local geo-environmental characteristics, twelve causative factors were selected, including elevation, slope angle, curvature, Topographic Wetness Index (TWI), Stream Power Index (SPI), lithology, rainfall, weathering crust, deeply separated density, drainage density, land use, and structural zones.

Elevation, slope angle, curvature, TWI, SPI, deeply separated density, and drainage density have been created and extracted using DEM which was explored from a Sentinel-1 image with the resolution of $12.5 \mathrm{~m}$ acquired from https://search.asf.alaska.edu/.

Land use map was collected and extracted from the Department of Agriculture and Rural Development of Hoa Binh Province at the scale of 1:50,000 in 2016.

Lithological, structural zone and weathering crust maps were prepared and extracted from Hoa Binh lithological, structural zone, and weathering crust maps at a scale of 50,000, which were supplied by the Ministry of Natural Resources and Environment of Vietnam.

Rainfall map was generated using the Inverse Distance Weighted method based on meteorological data in the period of 1999-2019.

All mentioned factors were converted into raster maps with pixel sizes of $12.5 \mathrm{~m} \times 12.5 \mathrm{~m}$.

\subsection{Flash Flood Susceptibility Mapping}

Entropy describes the disorder, instability, imbalanced behavior, energy distribution, and uncertainty in a system [17]. More precisely, entropy index as a measure of the average difference between a unit's group proportions and that of the system as a whole [18]. This theory was firstly proposed by Stephan Boltzmann and it was finally presented quantitatively by Shannon (1948) [17]. Furthermore, entropy presents the importance of variables that are more influence to flood occurrence [12]. Entropy values can be applied to calculate the target weight of the index system [19]. Thus, Shannon entropy is a function of probability distribution and the criterion for measurement of the amount of its uncertainty [8] as follows:

$$
\begin{aligned}
& P_{i j}=\frac{(B / A)}{\sum_{j=1}^{n}(B / A)} \\
& E_{j}=-\frac{1}{\ln (n)} \sum_{j=1}^{n} P_{i j} \ln \left(P_{i j}\right) \\
& D_{j}=1-E_{j}, j=1, \ldots, n \\
& W_{j}=\frac{D_{j}}{\sum_{j=1}^{n} D_{j}}
\end{aligned}
$$

Where A and B are the domain and flash flood percentages, $\mathrm{Pij}$ is the probability density, $\mathrm{n}$ is the number of classes for each causative factor, $\mathrm{Ej}$ shows entropy values, $D_{j}$ is the degree of diversification shows how much proper information the jth criterion gives to the decision-maker, and $\mathrm{W}_{\mathrm{j}}$ represents the resultant weight value for the factor as a whole.

The $\mathrm{W}_{\mathrm{j}}$ value ranges between 0 and 1 . The closer the $W_{j}$ value is to the number 1 , the greater the imbalance is, and in reverse [12] .

A Flash Flood Susceptibility Index (FFSI) map was calculated as the following equation:

$$
F F S I=\sum_{j=1}^{n}\left(W_{j} P_{j}\right)
$$

Where $\mathrm{Wj}$ and $\mathrm{Pj}$ are the final weight and the probability density for the $\mathrm{j}^{\text {th }}$ factor. 
Table 1 Spatial relationship between flash flood causative factors and flash flood locations using Shannon’s Entropy model.

\begin{tabular}{|c|c|c|c|c|c|c|c|c|c|}
\hline Data layer & Class & $\begin{array}{l}\text { Class } \\
\text { pixel }\end{array}$ & $\begin{array}{c}\% \\
\text { class } \\
\text { pixels } \\
\text { (A) } \\
\end{array}$ & $\begin{array}{l}\text { Flash } \\
\text { flood } \\
\text { pixels }\end{array}$ & $\begin{array}{l}\text { \% Flash } \\
\text { flood } \\
\text { pixels } \\
\text { (B) }\end{array}$ & $P_{i j}$ & $\mathrm{E}_{\mathrm{j}}$ & $\mathrm{D}_{\mathrm{j}}$ & $\mathrm{W}_{\mathrm{j}}$ \\
\hline \multirow{5}{*}{$\begin{array}{l}\text { Elevation } \\
\quad(\mathrm{m})\end{array}$} & $5.0-230.0$ & 694189 & 0.34 & 6093.75 & 0.44 & 0.368 & -0.160 & 0.219 & 0.084 \\
\hline & $230.0-473.0$ & 695907 & 0.35 & 6093.75 & 0.44 & 0.367 & -0.160 & & \\
\hline & $473.0-869.0$ & 259597 & 0.13 & 1093.75 & 0.08 & 0.176 & -0.133 & & \\
\hline & 869.0 - 1017.0 & 219798 & 0.11 & 468.75 & 0.03 & 0.089 & -0.094 & & \\
\hline & 1017.0 - 1253.0 & 143253 & 0.07 & 0.00 & 0.00 & 0.000 & 0.000 & & \\
\hline \multirow{5}{*}{$\begin{array}{c}\text { Slope } \\
\text { (degree) }\end{array}$} & $0-14.4$ & 718900 & 0.36 & 7500 & 0.55 & 0.361 & -0.160 & 0.055 & 0.021 \\
\hline & $14.4-28.2$ & 483352 & 0.24 & 2812.5 & 0.20 & 0.202 & -0.140 & & \\
\hline & $28.2-40.2$ & 437646 & 0.22 & 2187.5 & 0.16 & 0.173 & -0.132 & & \\
\hline & $40.2-59.2$ & 274542 & 0.14 & 781.25 & 0.06 & 0.099 & -0.099 & & \\
\hline & $59.2-78.3$ & 98304 & 0.05 & 468.75 & 0.03 & 0.165 & -0.129 & & \\
\hline \multirow{5}{*}{ Curvature } & $(-35.84)-(-1.92)$ & 182091 & 0.09 & 625 & 0.05 & 0.121 & -0.111 & 0.032 & 0.012 \\
\hline & $(-1.92)-(-0.64)$ & 599914 & 0.30 & 4531.25 & 0.33 & 0.266 & -0.153 & & \\
\hline & $(-0.64)-0.64$ & 798137 & 0.40 & 6250 & 0.45 & 0.275 & -0.154 & & \\
\hline & $0.64-2.56$ & 387416 & 0.19 & 2187.5 & 0.16 & 0.199 & -0.139 & & \\
\hline & $2.56-53.12$ & 39254 & 0.02 & 156.25 & 0.01 & 0.140 & -0.120 & & \\
\hline \multirow{5}{*}{ TWI } & $1.22-4.61$ & 501400 & 0.25 & 2500 & 0.18 & 0.118 & -0.109 & 0.045 & 0.017 \\
\hline & $4.61-5.96$ & 801483 & 0.40 & 4062.5 & 0.30 & 0.120 & -0.110 & & \\
\hline & $5.96-7.79$ & 467087 & 0.23 & 4218.75 & 0.31 & 0.213 & -0.143 & & \\
\hline & $7.79-10.23$ & 171926 & 0.09 & 2343.75 & 0.17 & 0.322 & -0.158 & & \\
\hline & $10.23-18.37$ & 64772 & 0.03 & 625 & 0.05 & 0.228 & -0.146 & & \\
\hline \multirow{5}{*}{ SPI } & $0-722.6$ & 1984477 & 0.99 & 13750.00 & 1.00 & 1.000 & 0.000 & 1.000 & 0.383 \\
\hline & 722.6 - 3251.7 & 17946 & 0.01 & 0.00 & 0.00 & 0.000 & 0.000 & & \\
\hline & 3251.7 - 8309.9 & 3153 & 0.00 & 0.00 & 0.00 & 0.000 & 0.000 & & \\
\hline & 8309.9 - 17703.8 & 900 & 0.00 & 0.00 & 0.00 & 0.000 & 0.000 & & \\
\hline & > 17703.8 & 192 & 0.00 & 0.00 & 0.00 & 0.000 & 0.000 & & \\
\hline \multirow{5}{*}{ Lithology } & $\begin{array}{c}\text { Quaternary } \\
\text { sedimentary rocks }\end{array}$ & 311135 & 0.16 & 4062.50 & 0.30 & 0.456 & -0.155 & 0.208 & 0.080 \\
\hline & $\begin{array}{c}\text { Carbonate } \\
\text { sedimentary rocks }\end{array}$ & 668904 & 0.33 & 3593.75 & 0.26 & 0.188 & -0.136 & & \\
\hline & $\begin{array}{l}\text { Aluminosilicate- } \\
\text { rich sedimentary } \\
\text { rocks }\end{array}$ & 874756 & 0.44 & 5625.00 & 0.41 & 0.225 & -0.146 & & \\
\hline & Acid-magma rocks & 20507 & 0.01 & 0.00 & 0.00 & 0.000 & 0.000 & & \\
\hline & $\begin{array}{l}\text { Mafic erupted } \\
\text { rocks }\end{array}$ & 124746 & 0.06 & 468.75 & 0.03 & 0.131 & -0.116 & & \\
\hline \multirow{5}{*}{ Rainfall } & $1401-1528$ & 178293 & 0.09 & 468.75 & 0.03 & 0.092 & -0.095 & 0.134 & 0.051 \\
\hline & $1528-1587$ & 428804 & 0.21 & 1718.75 & 0.13 & 0.140 & -0.120 & & \\
\hline & $1587-1641$ & 79840 & 0.04 & 937.50 & 0.07 & 0.410 & -0.159 & & \\
\hline & $1641-1703$ & 87172 & 0.04 & 156.25 & 0.01 & 0.063 & -0.075 & & \\
\hline & $1703-1764$ & 1238664 & 0.62 & 10468.75 & 0.76 & 0.295 & -0.156 & & \\
\hline \multirow{4}{*}{$\begin{array}{l}\text { Weathering } \\
\text { crust }\end{array}$} & Sialferit & 895245 & 0.45 & 5625.00 & 0.41 & 0.221 & -0.145 & 0.082 & 0.031 \\
\hline & Ferosialit-Sialferit & 124736 & 0.06 & 468.75 & 0.03 & 0.132 & -0.116 & & \\
\hline & Sialferit-Sialit & 668868 & 0.33 & 3593.75 & 0.26 & 0.189 & -0.137 & & \\
\hline & Ferosialit & 311098 & 0.16 & 4062.50 & 0.30 & 0.459 & -0.155 & & \\
\hline
\end{tabular}




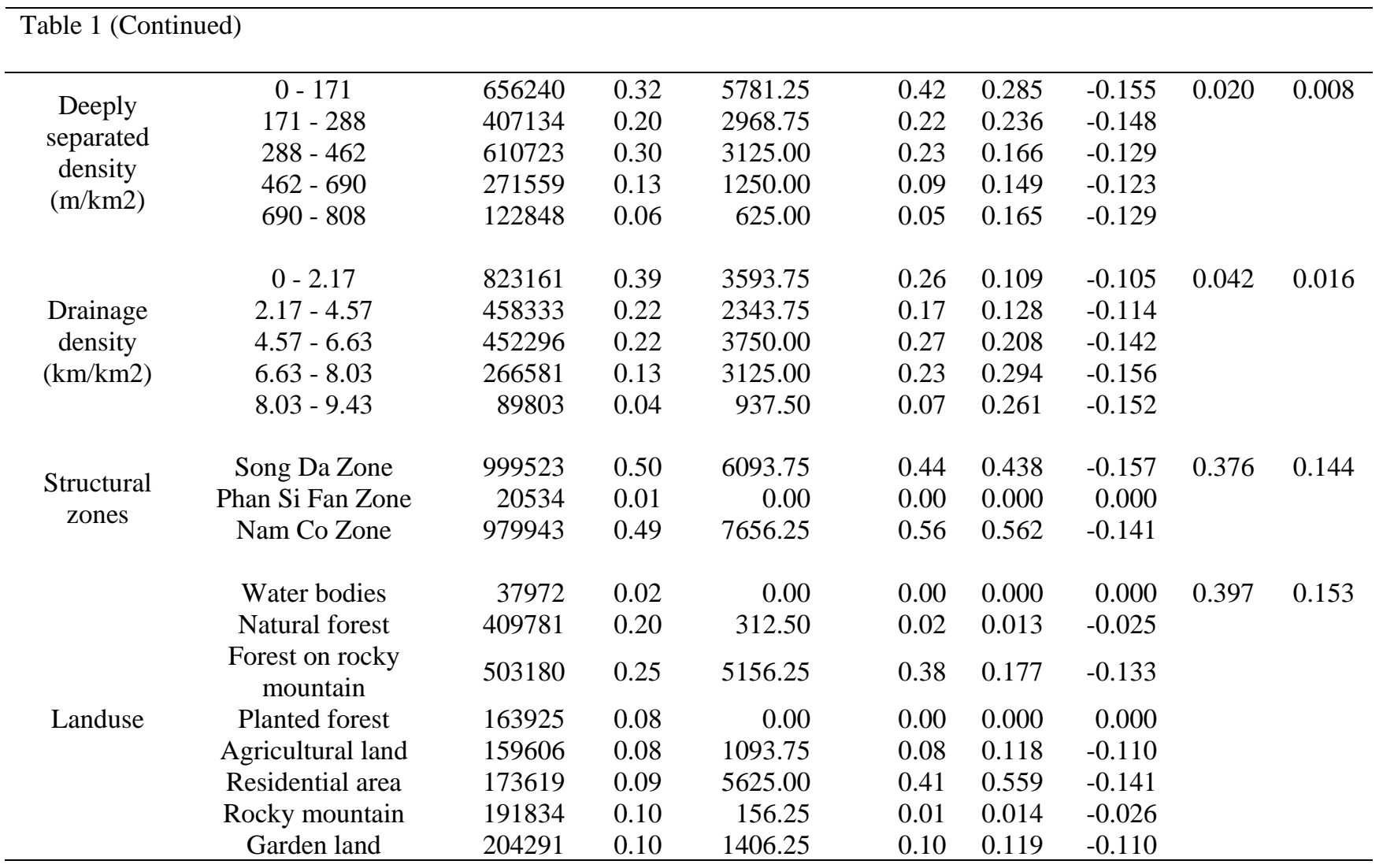

Whereafter, this FFSI map is reclassified to develop a detailed flash flood forecasting map. This map was classified based on the Natural Break classification scheme into very low, low, moderate, high, and very high susceptibility classes.

\subsection{Validation of Shannon's Entropy Model}

Validation is an essential part of the development and evaluation of the obtained maps from different methods [17]. Without the validation of the performance, a forecasting map has not scientific meaning.

The area under the curve (AUC) of the receiver operating characteristic (ROC) reflects the quality of a forecasting map by showing the system's ability to expect the correct occurrence or nonoccurrence of pre-defined "events" [13]. Qualitative-quantitative correlation relationship between AUC and prediction accuracy is classified as follows: $0.9-1$ : perfect; $0.8-0.9$ : very good; $0.7-$ 0.8: good; 0.6-0.7: medium and 0.5-0.6: weak [15, 17]. In the present study, AUC was applied to estimate the accuracy of the flash flood forecasting map.

\section{RESULTS AND DISCUSSION}

\subsection{Entropy Values of Flash Flood Causative Factors}

In this study, entropy values were calculated for flash flood causative factors by using relations presented in Shannon's Entropy model (Table 1).

The weight of the elevation was 0.084 , while the slope angle has a weight of 0.021 , the curvature of 0.012 , and a deeply separated density of 0.008 . This indicated the importance of elevation between the topographic parameters in the study area.

The relationship between hydrological parameters such as TWI, SPI, and drainage density with flash flood occurrences expressed the weight of $0.017,0.383$, and 0.016 , respectively which showed the SPI was the most important factor among hydrological indices.

The weight of the geological factors such as weathering crust, lithology, and structural zones were $0.031,0.080$, and 0.144 , respectively which indicated the importance of the structural zones between the other geological indices.

Investigation on rainfall represented that this factor weights 0.051 , while land uses weights 0.153 . According to the results, it is considered that SPI, land use, and structural zones, have the strongest importance on the flash flood prediction map in the study area (values of $0.383,0.153$, and 0.144 , respectively).

In contrast, factors such as deeply separated density, curvature, drainage density, and TWI had the lowest effect on flash flood forecasting maps (values of 0.008, 0.012, 0.016, and 0.017, respectively). 
The result of Shannon's Entropy and the relationship between flash flood occurrence and flash flood causative factors is presented in Table 1.

\subsection{Flash Flood Forecasting Map}

To determine the spatial relationship between flash flood locations and flash flood influencing factors, the SE method was used in this study. In this method, the final weight $(\mathrm{Wj})$ results express that the highest weight is assigned to factors of SPI, land use, and structural zones $(0.383,0.153$, and 0.144 ), while the lowest is assigned to factors of deeply separated density, curvature, drainage density, and TWI (0.008, 0.012, 0.016, and 0.017). According to the calculated analysis results, the flash flood forecasting map along NH-6 was developed using Shannon's Entropy model based on 12 factors affecting flash flood occurrence in the study area (Fig.3).

The Weighted Sum tool in ArcGIS was used to overlay the $\mathrm{Wj}$ values of twelve flash flood causative factors, to generate a flash flood susceptibility index (FFSI) map.

In this study, the calculated FFSI value ranges from 1.268 to 4.544 (Fig.3). This index demonstrates the susceptibility degree of the area to flash flood occurrences.

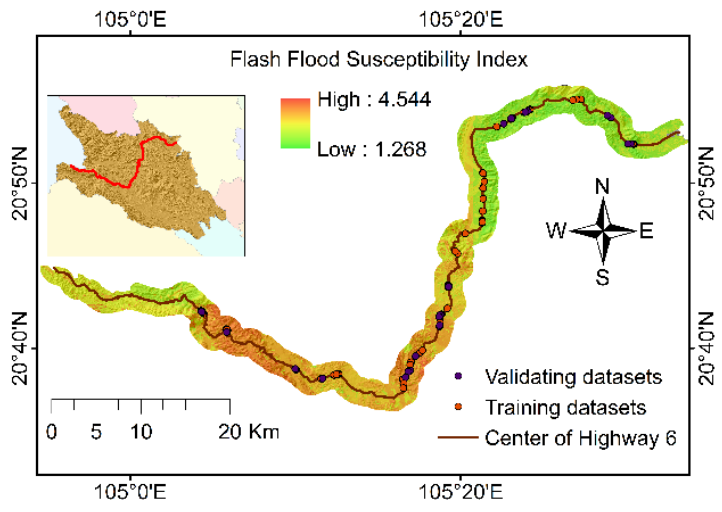

Fig.3 Flash flood susceptibility index map along NH-6.

Whereafter, the FFSI map was reclassified into five susceptiblity groups, including very low, low, moderate, high, and very high, using the Natural Breaks method.

The classification of the flash flood prediction map provides useful information to estimate the flash flood possibility in each factor and for visually describing predicted hazardous zones in the study area [1].

The flash flood susceptibility distribution in the study area is presented in Fig.4.

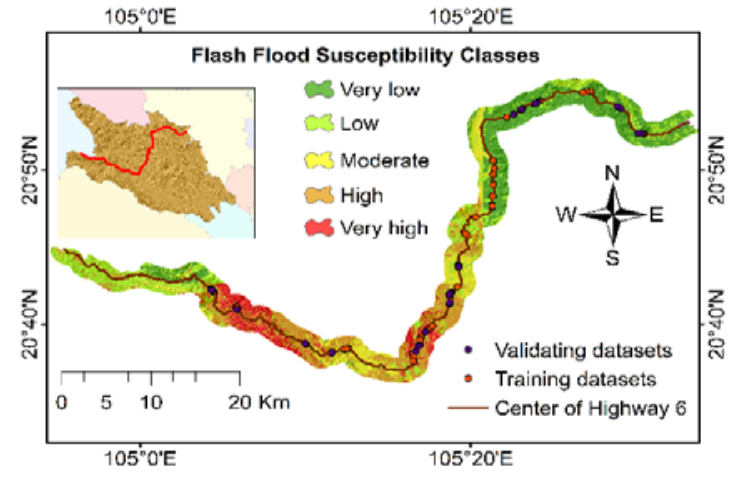

Fig.4 Flash flood forecasting map along NH-6.

From the analysis of the flash flood forecasting map, it can be seen that $27.85 \%$ of the study area is located in the very low susceptibility regions, $25.33 \%$ in the low susceptibility regions, $14.56 \%$ in the moderate susceptibility regions, $22.97 \%$ in the high susceptibility regions, while $9.28 \%$ in the very high susceptibility regions (Table 2).

Table 2 The distribution of the flash flood susceptibility values and areas correspond to the flash flood occurrence potential zones.

\begin{tabular}{clc}
\hline $\begin{array}{c}\text { Flash flood } \\
\text { susceptibility } \\
\text { degree }\end{array}$ & \multicolumn{2}{c}{ Shannon’s Entropy Model } \\
\cline { 2 - 3 } Rery low & $1.27-1.89$ & Area (\%) \\
Low & $1.89-2.24$ & 25.33 \\
Moderate & $2.24-2.50$ & 14.56 \\
High & $2.50-2.74$ & 22.97 \\
Very high & $2.74-4.54$ & 9.28 \\
\hline
\end{tabular}

The ROC curve method is one of the most popular techniques for evaluating the efficiency of the models since it estimates the result of the model and quantitatively calculates efficiency [8]. Thus, in the present study, the ROC curve method was employed to evaluate the accuracy of flash flood potential map.

A total number of 104 flash flood locations were collected, while 73 flash flood locations (70\% flash flood inventory) were selected to develop the flash flood potential map, and 31 flash flood locations (30\% remaining flash flood inventory) were applied to validate the SE model performance.

The performance of Shannon's Entropy model is very good. Meanwhile, the AUC value of the success rate curve is 0.834 with the training dataset (Fig.5) and the AUC value of the success rate curve is 0.811 with the validating dataset (Fig.6), respectively. 


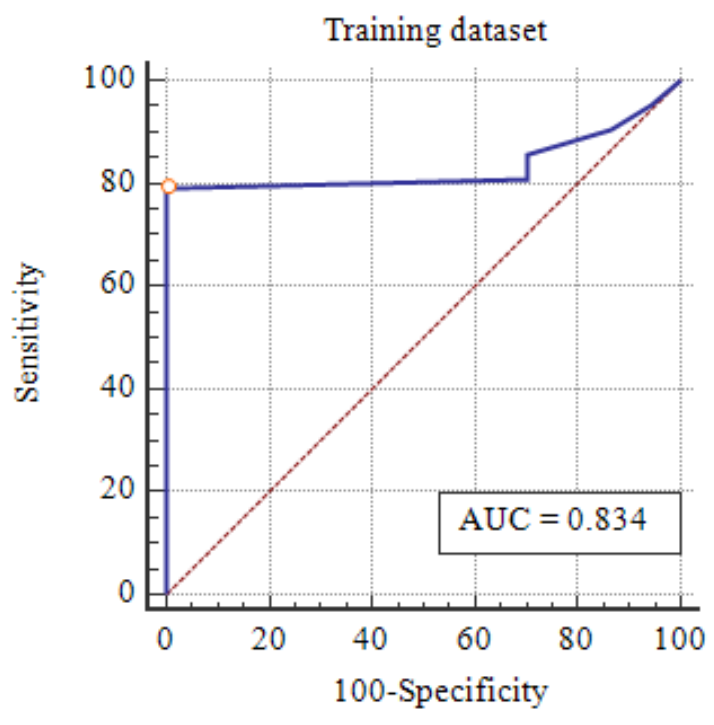

Fig.5 ROC curve of flash flood forecasting map with the training dataset using Shannon's Entropy model.

The validation result shows that the flash flood forecasting map in this study has had an accuracy of $81.10 \%$.

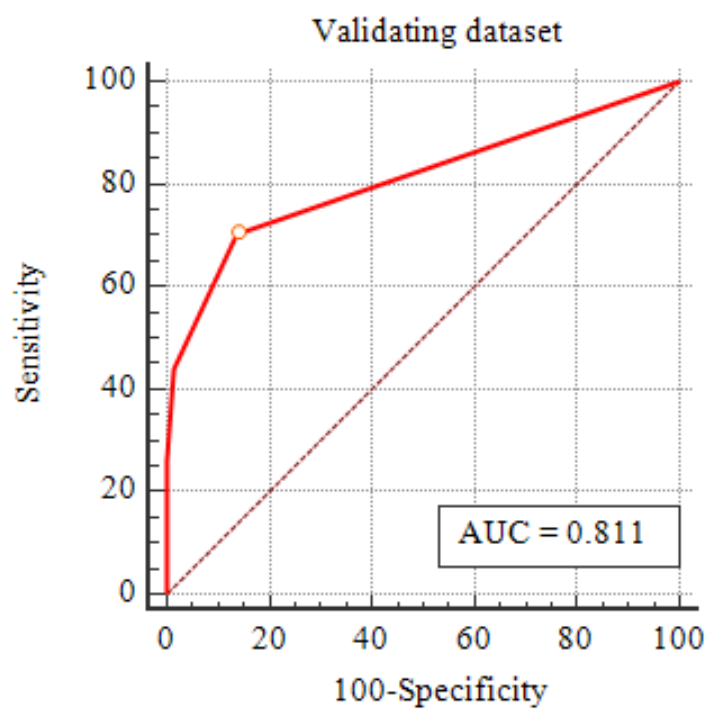

Fig.6 ROC curve of flash flood forecasting map with the validating dataset using Shannon's Entropy model.

\section{CONCLUSION}

A flash flood susceptibility map can indicate future flash flood occurrence areas within the research area, so it provides the background to recognize areas affecting flash flood events, planning for risk management, prevention, and mitigation. In this study, flash flood susceptibility areas have been identified using the SE method and
GIS. In the first step, a flash flood inventory map containing 104 flash flood locations was collected from field surveys and historical data. Then, 12 flash flood causative factors (elevation, slope angle, curvature, Topographic Wetness Index, Stream Power Index, lithology, rainfall, weathering crust, deeply separated density, drainage density, land use, and structural zones) were prepared in ArcGIS 10.5 software. In the third step, the flash flood forecasting map was developed using Shannon's Entropy model. Finally, the ROC curve was used to evaluate the accuracy of the resulting map. The validation results demonstrate that Shannon's Entropy has a very good performance in recognizing flash flood potential zones along NH-6, Hoa Binh province, Vietnam (AUC=0.811).

The scientific information obtained from this study can be used for disaster management, planning, and others to conduct suitable safety and rescue measures or give early warning to people who have lived along this highway in order to reduce flash flood damage in the future.

In addition, the flash flood susceptibility map also indicates Shannon's Entropy model is an effective, fast, easy to use, and updated method in evaluating flash flood susceptibility zones on mountainous highways, even in limited data areas. According to that, the SE method also has shorttime data processing. Therefore, this approached model is quite suitable for road manager units in mountainous areas because of the limitation of the technology, software, human, and degree.

In the current study, the structural parameters of the road have not been mentioned because of the time limitation. Moreover, the resulting map of this study can help road manager units in conducting suitable technical solutions along this highway in order to flash flood damage reduction and road infracstructure protection.

\section{ACKNOWLEDGMENTS}

This research is funded by National University of Civil Engineering (NUCE) under grant number 23-2019/KHXD-TĐ.

\section{REFERENCES}

[1] Ha T. H., Pham D. H., Vu N. T., and Nguyen V. P., Landslide Susceptibility Mapping Along National Highway-6, Hoa Binh province, Vietnam Using Frequency Ratio Model and GIS. International Journal of GEOMATE, Vol.21, Issue 85, 2021, pp.84-90.

[2] Spreafico M., Flash Floods in Mountain Areas. Climate Variability and Change-Hydrological Impacts, Vol.308, 2006, 7p.

[3] Pham T. T. N., Nong D., Sathyan A. R., and Garschagen M., Vulnerability Assessment of 
Households to Flash Floods and Landslides in The Poor Upland Regions of Vietnam. Climate Risk Management, Vol.28, Issue 100215, 2020, 42p.

[4] Bui D. P., Hoang T., Nguyen P. V., Ngo D. V., and Cao C. P., Influence of Distance Between Cement-fly Ash-gravel Piles on The Foundation Treatment in Vietnam. International Journal of GEOMATE, Vol.20, Issue 79, 2021, pp. 104110.

[5] Nguyen V. P., Pham D. H., Bui P. D., Bui N. T., and Nguyen D. V. A., Research The Possibility of Using Sea Sand in Roaded Construction in Vietnam. International Journal of GEOMATE, Vol.20, Issue 77, 2021, pp. 123-131.

[6] Nguyen V. P., Pham T. H., Ung T. T. H., Hoang T., and Tong N. T., Proposal of A Set of Quantitative Criteria For Evaluating and Classifying Urban Street Flooding Spots in Vietnam. IOP Conference Series: Materials Science and Engineering, Vol.869, 2020, 10p.

[7] Ha H., Luu C., Bui D. Q., Pham D. H., Hoang T., Nguyen V. P., Vu M. T., and Pham B. T., Flash Flood Susceptibility Prediction Mapping For A Road Network Using Hybrid Machine Learning Models. Natural Hazards, 2021, pp. 124.

[8] Khosravi K., Pourghasemi H. R., Chapi K., and Bahri M., Flash Flood Susceptibility Analysis And Its Mapping Using Different Bivariate Models In Iran: A Comparison Between Shannon's Entropy, Statistical Index, and Weighting Factor Models. Environmental monitoring and assessment, Vol. 188, Issue 12, 2016, pp. 1-21.

[9] Youssef A. M., Pradhan B., and Hassan A. M., Flash Flood Risk Estimation Along The St. KatherineR, Southern Sinai, Egypt Using GIS Based Morphometry And Satellite Imagery. Environmental Earth Sciences, Vol.62, 2011, pp.611-623.

[10] Goumrasa A., Guendouz M., Guettouche M. S., and Belaroui A., Flood Hazard Susceptibility Assessment in Chiffa wadi Watershed and Along The First Section of Algeria North-South Highway Using GIS and AHP method. Applied Geomatics, 2021, pp. 1-21.

[11] Ha T. H., Hoang T., Pham D. H., Nguyen V. P., Tran V. P., Costache, R., Nguyen H. D., Amiri M., Le H. A., Le H. V., Prakash I. and Pham B. T., Spatial Prediction of Landslides
Along National Highway-6, Hoa Binh Province, Vietnam Using Novel Hybrid Models. Geocarto International, 2021, pp.1-26.

[12] Haghizadeh A., Siahkamari S., Haghiabi A. H., and Rahmati O., Forecasting Flood-prone Areas Using Shannon's Entropy Model.,” Journal of Earth System Science, Vol. 126, Issue 3, 2017, 39p.

[13] Naghibi S. A., Pourghasemi H. R., Pourtaghi Z. S., and Rezaei A., Groundwater Qanat Potential Mapping Using Frequency Ratio and Shannon's Entropy Models in The Moghan Watershed, Iran. Earth Science Informatics, Vol. 8, Issue 1, 2015, pp. 171-186.

[14] Ha T. H.,Application of Remote Sensing and GIS for Flood Vulnerability and Mitigation: A Case Study of Flood Affected Highway 6, Hoa Binh Province. The International Conference on GeoInformatics for Spatial-Infrastructure Development in Earth \& Allied Sciences, 2018, pp. 205-210.

[15] Pradhan B., Groundwater Potential Zonation For Basaltic Watersheds Using Satellite Remote Sensing Data and GIS Techniques. Central European Journal of Geosciences, Vol. 1, Issue 1, 2009, pp. 120-129.

[16] Oh H. J. and Pradhan B., Application Of A Neuro-fuzzy Model To Landslide Susceptibility Mapping For Shallow Landslides In A Tropical Hilly Area. Computers \& Geosciences, Vol. 37, Issue 9, 2011, pp.1264-1276.

[17] Pourghasemi H. R., Mohammady M., and Pradhan B., Landslide Susceptibility Mapping Using Index of Entropy and Conditional Probability Models in GIS: Safarood Basin, Iran. Catena, Vol.97, 2012, pp.71-94.

[18] Freeman D. H. and Theil H., Statistical Decomposition Analysis. Technometrics, Vol. 16, Issue 2, 1974, p.328.

[19] Yang Z., Qiao J., and Zhang X., Regional Landslide Zonation Based On Entropy Method in Three Gorges Area, China. Seventh International Conference on Fuzzy Systems and Knowledge Discovery, Vol. 3, 2010, pp. 13361339.

Copyright (C) Int. J. of GEOMATE All rights reserved, including making copies unless permission is obtained from the copyright proprietors. 